Supporting Information

\title{
Efficient Solid-state Electrolytes Based on Aryl-modified Imidazolium Ionic Crystals for Quantum-dots Sensitized Solar Cells
}

Guojiao Zhao ${ }^{\mathrm{a}, \mathrm{c}}$, Yefeng Wang, ${ }^{\mathrm{a}, \mathrm{b}, *}$, Jing-Hui Zeng, ${ }^{\mathrm{a}, \mathrm{c}, \mathrm{d}}$, Zhaofu Fei ${ }^{\mathrm{e}}$, Paul J. Dyson ${ }^{\mathrm{e}, *}$

a Shaanxi Provincial Key Laboratory of Macromolecular Science, 710119, Xi'an, China.

b School of Chemistry \& Chemical Engineering, Shaanxi Normal University, 710119, Xi'an, China.

c School of Material Science and Engineering, Shaanxi Normal University, 710119, Xi'an, China.

d Shaanxi Key Laboratory for Advanced Energy Devices and Shaanxi Engineering Lab for Advanced Energy Technology, 710119, Xi'an, China.

e Institute of Chemical Sciences and Engineering, École Polytechnique Fédérale de Lausanne (EPFL), 1015 Lausanne, Switzerland.

*To whom correspondence should be addressed. Email: wangyefeng@snnu.edu.cn, nanosci@snnu.edu.cn, paul.dyson@epfl.ch. 
Fig. S1 ${ }^{1} \mathrm{H},{ }^{13} \mathrm{C}$ and ${ }^{19} \mathrm{~F}$ NMR spectra and ESI-MS spectra for cation of 1-(9'-fluorenyl)-3-ethylimidazolium tetrafluoroborate ([FEIm] $\left.\mathrm{BF}_{4}\right)$.
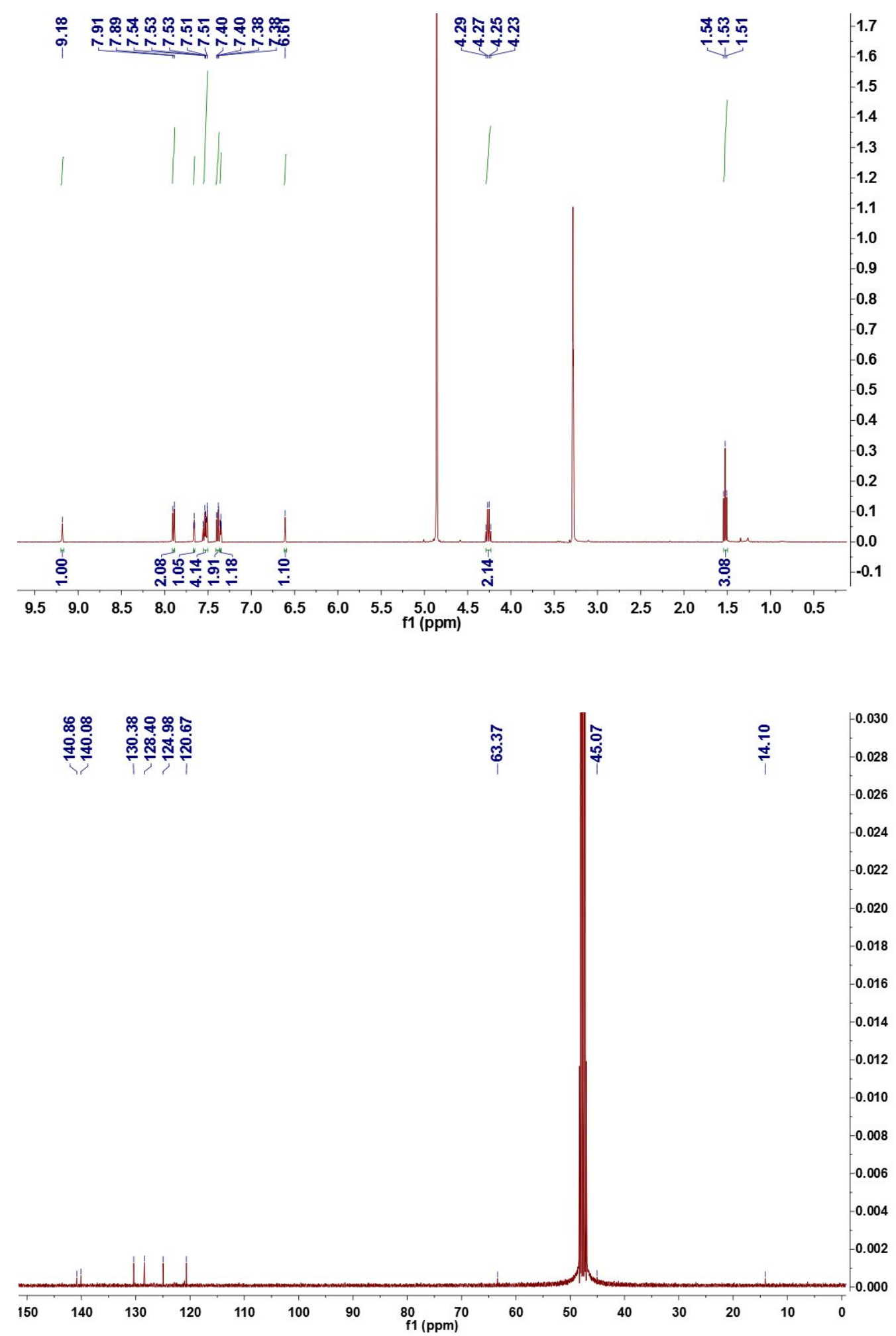

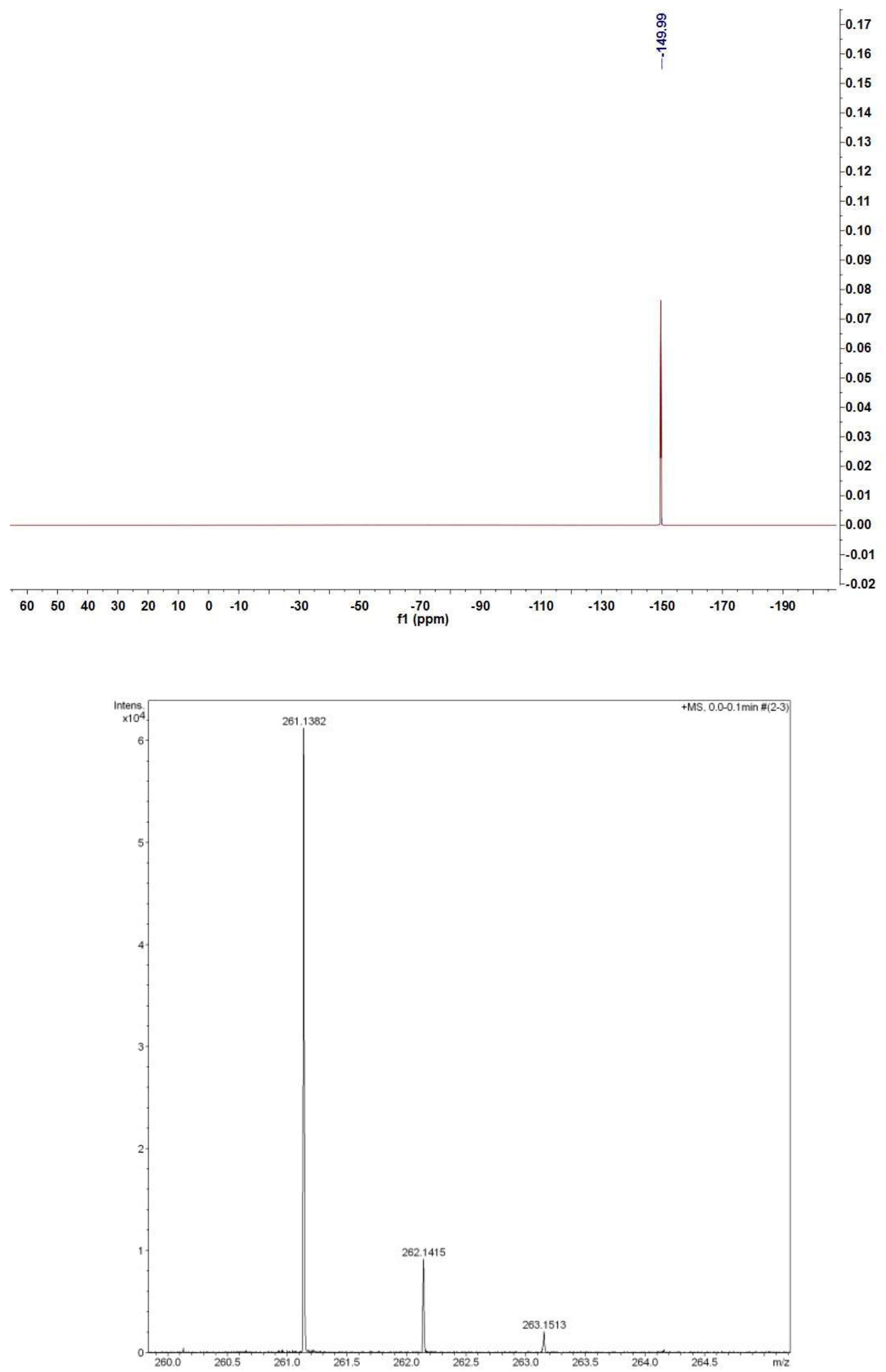
Fig. S2 ${ }^{1} \mathrm{H},{ }^{13} \mathrm{C}$ and ${ }^{19} \mathrm{~F}$ NMR spectra and ESI-MS spectra for cation of 1-diphenylmethyl-3-ethylimidazolium tetrafluoroborate ([DPMEIm]BF 4 ).
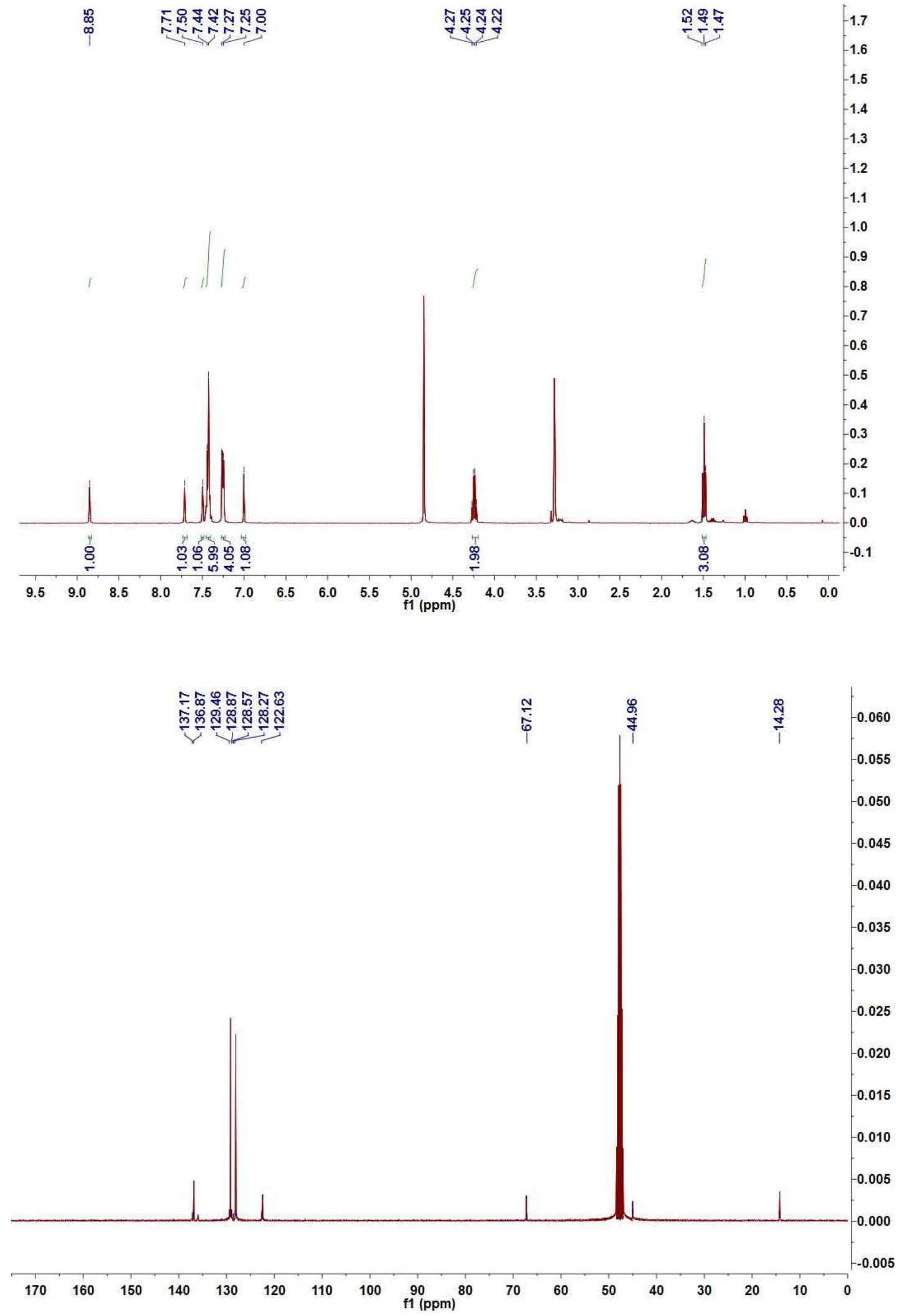

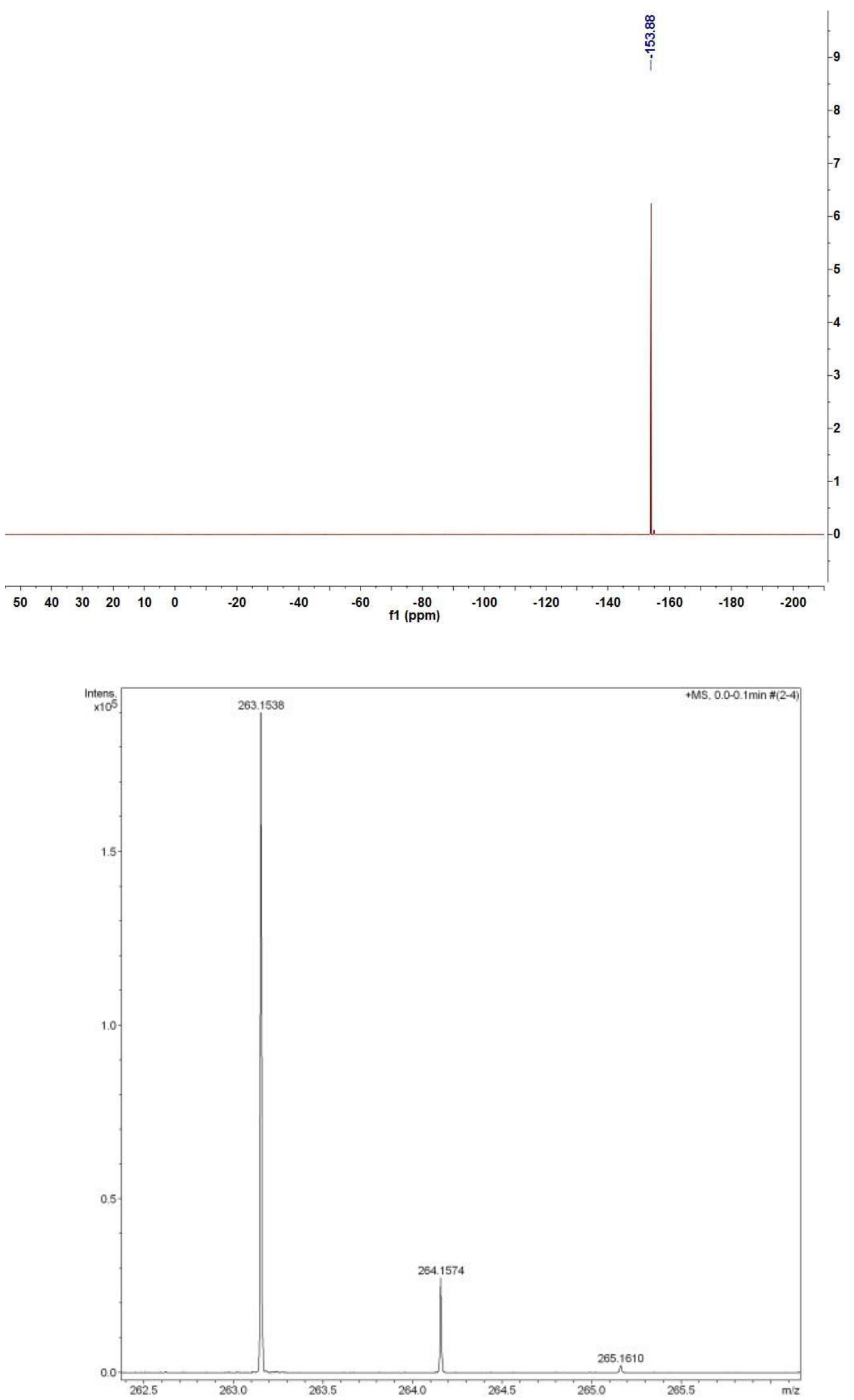

S5 
Fig. S3 ${ }^{1} \mathrm{H},{ }^{13} \mathrm{C}$ and ${ }^{19} \mathrm{~F}$ NMR spectra and ESI-MS spectra for cation of 1,3-bi(9'-fluorenyl)imidazolium tetrafluoroborate ([BFIm] $\left.\mathrm{BF}_{4}\right)$.
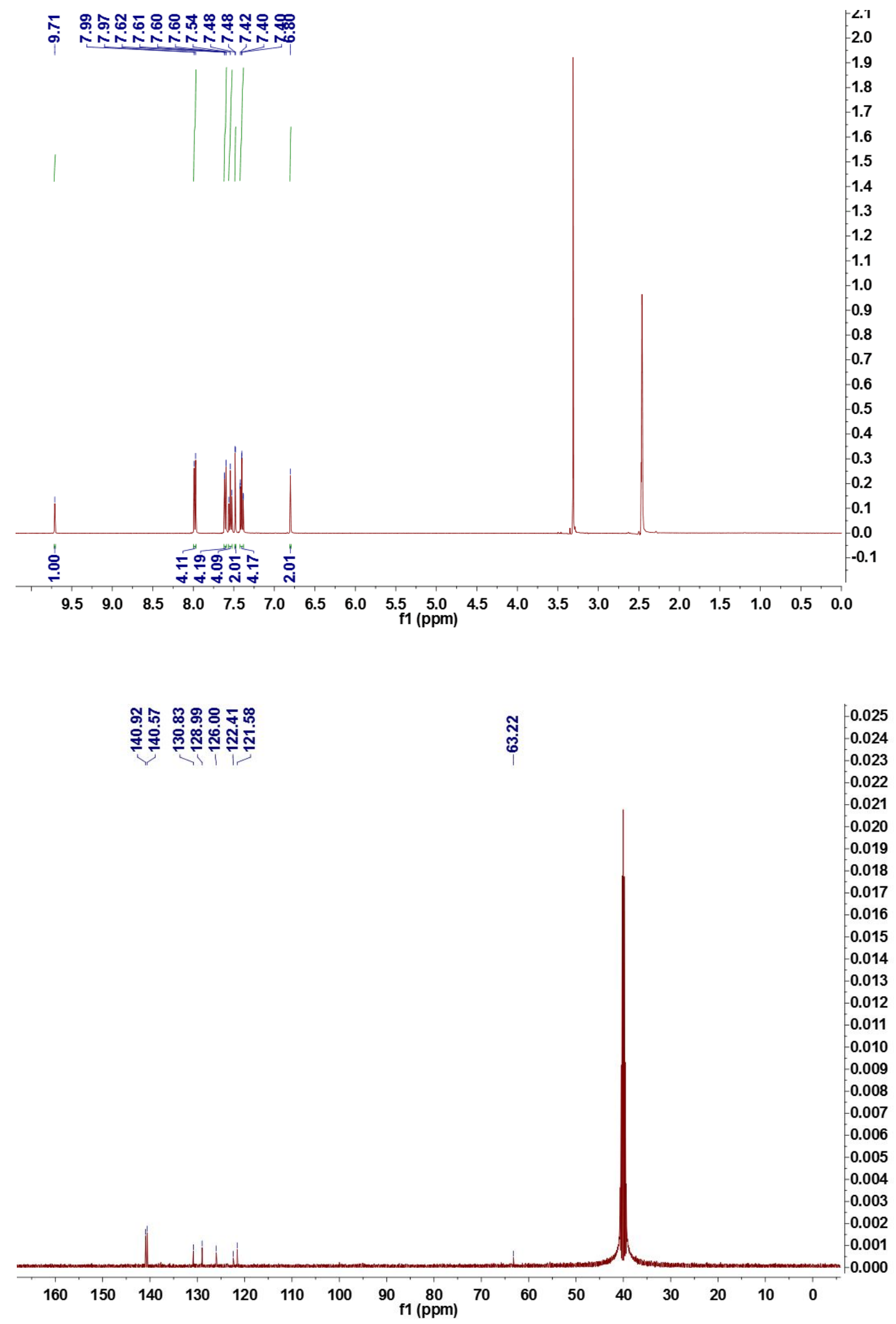

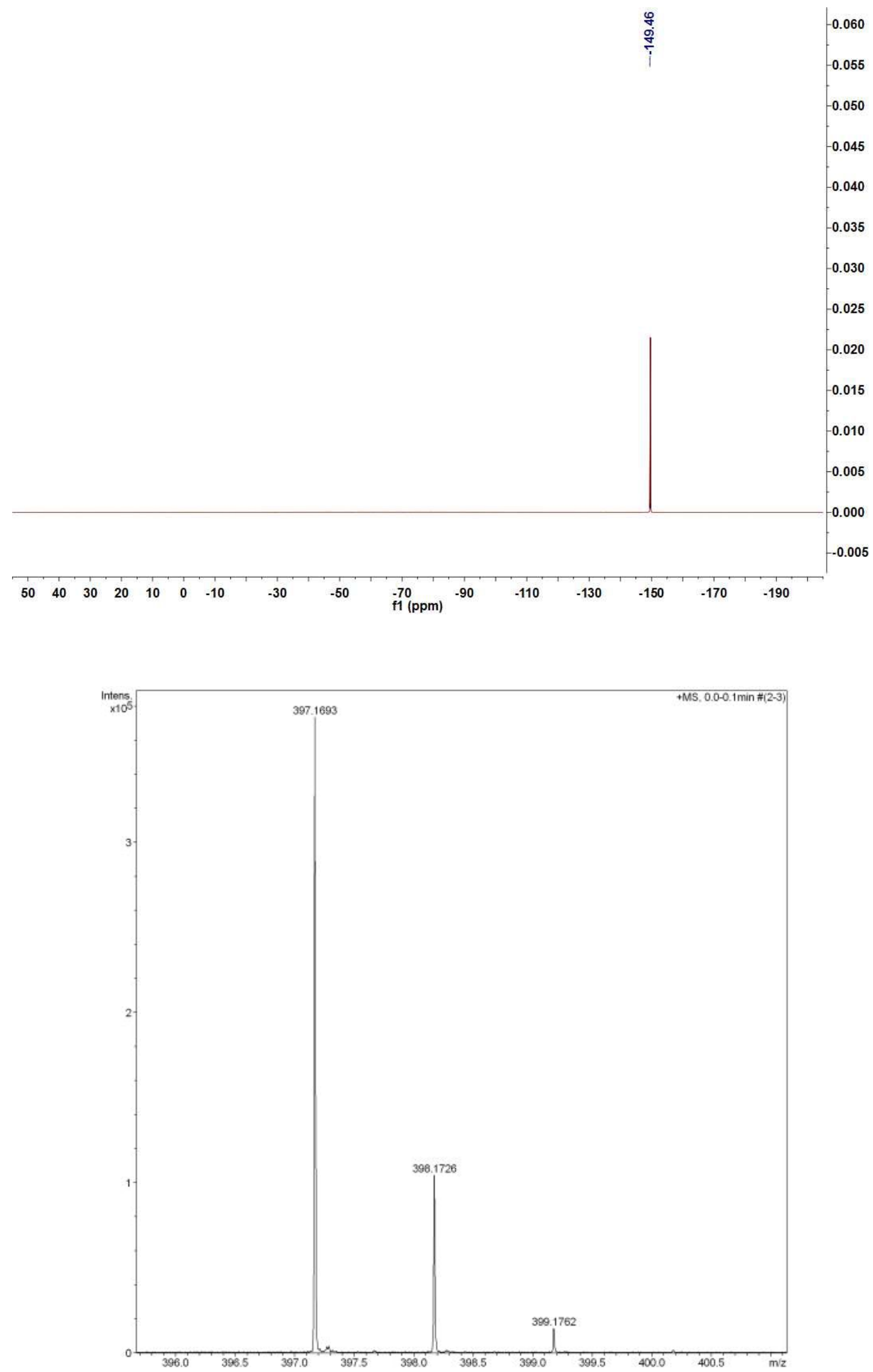
Fig. S4 ${ }^{1} \mathrm{H},{ }^{13} \mathrm{C}$ and ${ }^{19} \mathrm{~F}$ NMR and ESI-MS spectra for cation of 1,3-bi(diphenylmethyl)imidazolium tetrafluoroborate ([BDPMIm] $\left.\mathrm{BF}_{4}\right)$.
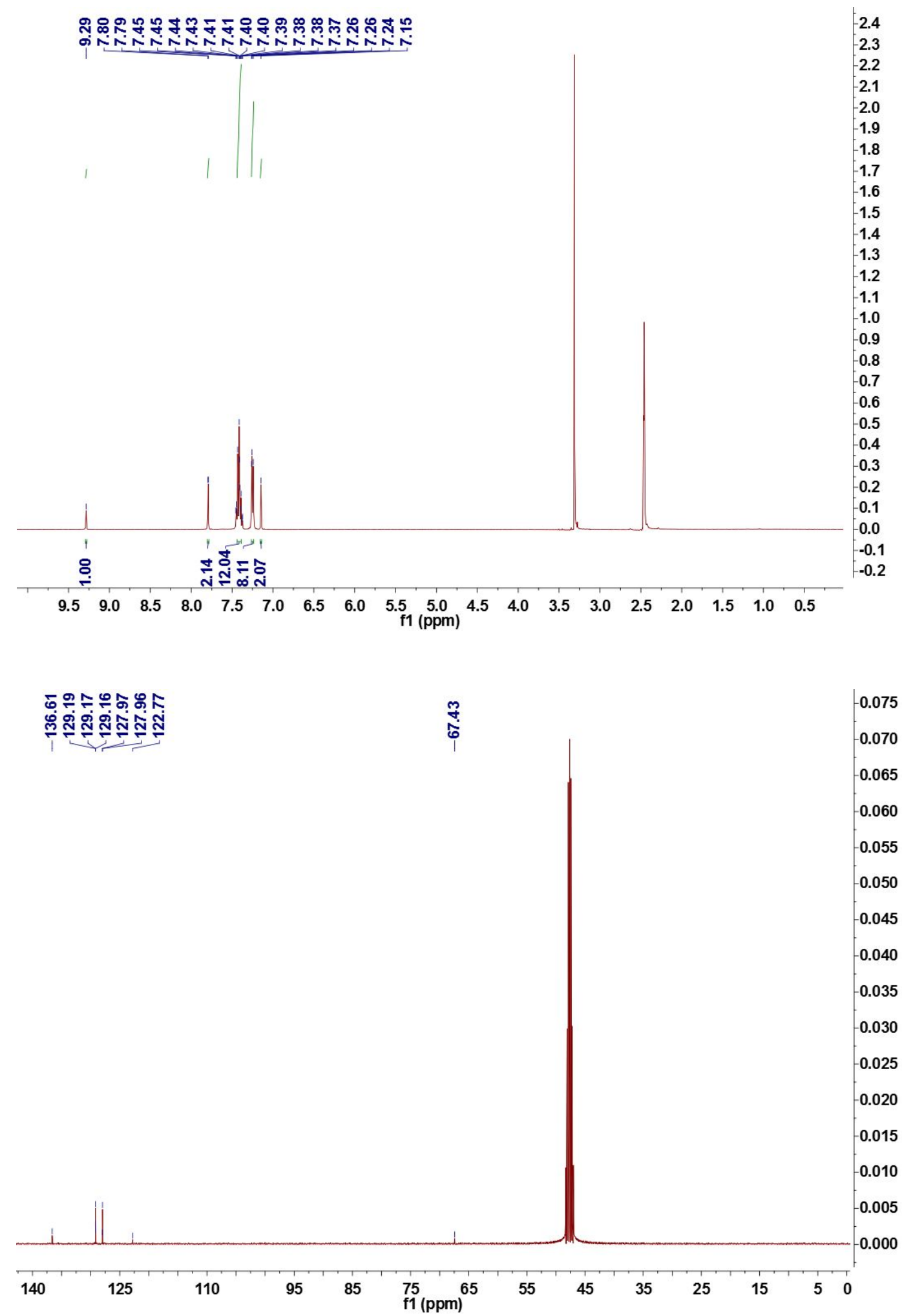

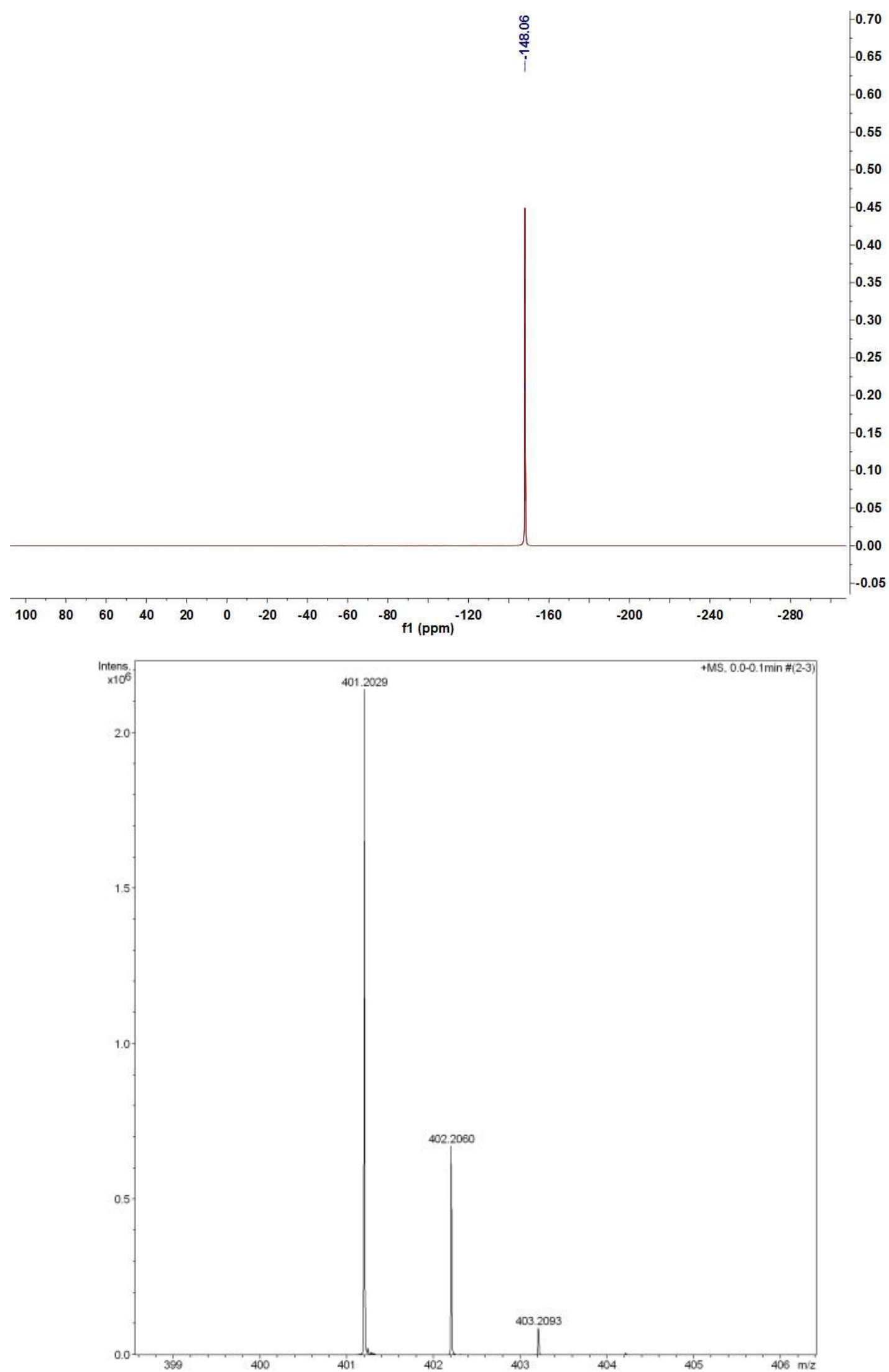


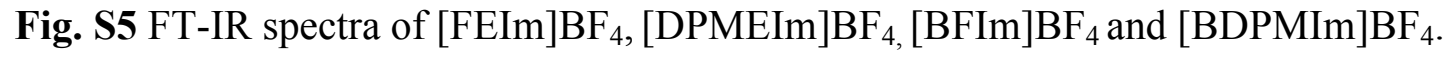

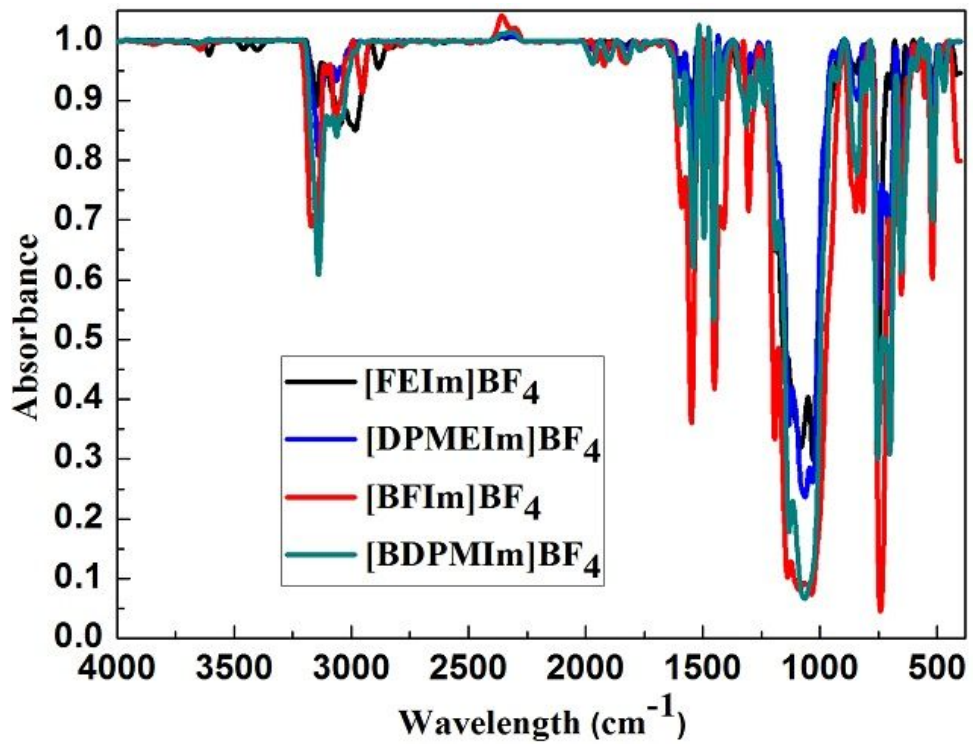

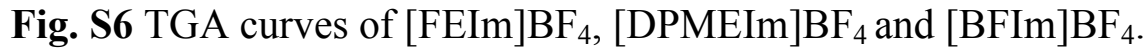

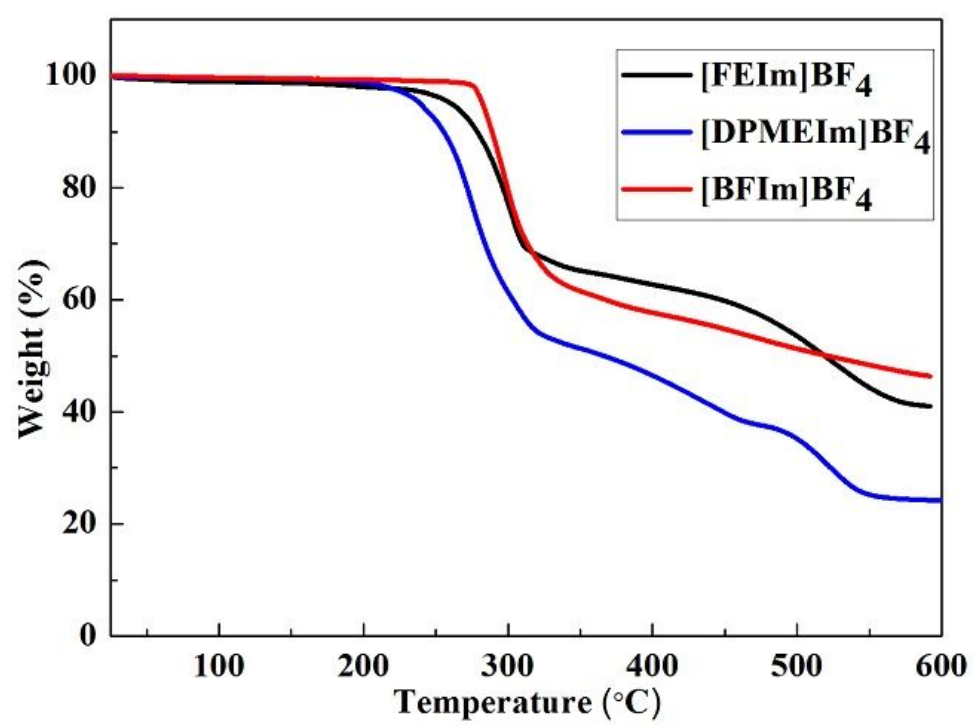




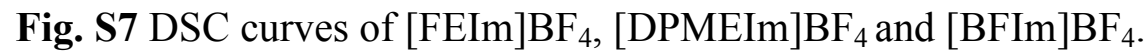

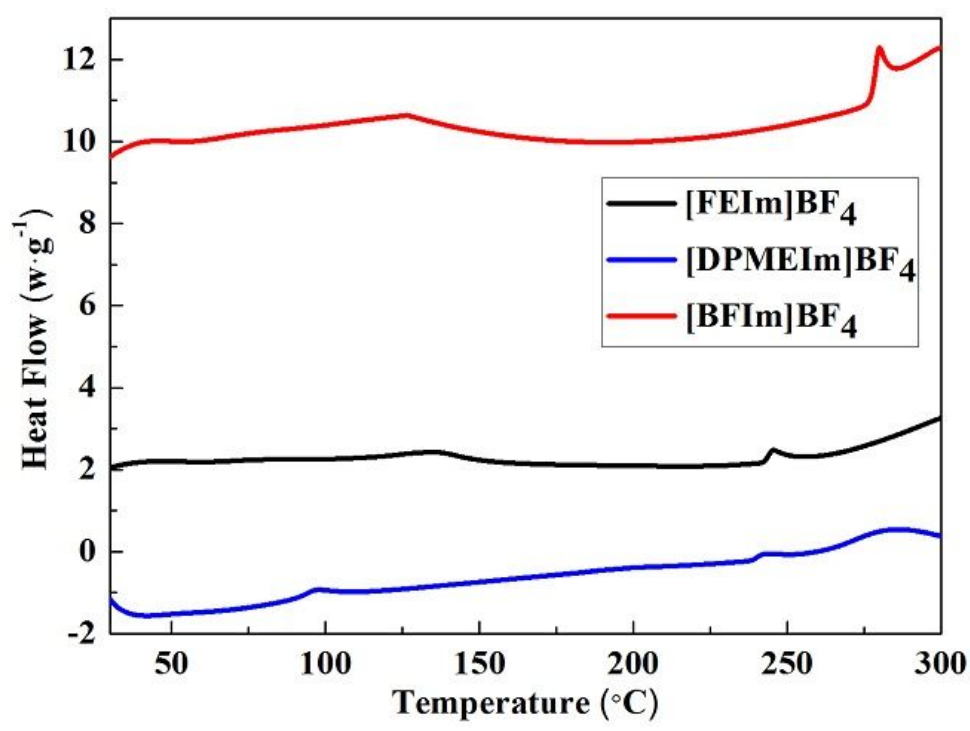

Fig. S8 IPCE spectra of the QDSSCs with the solid-state electrolytes based on

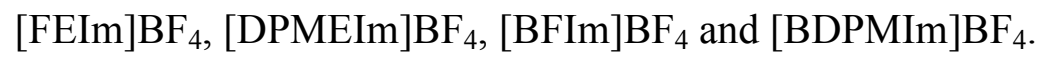

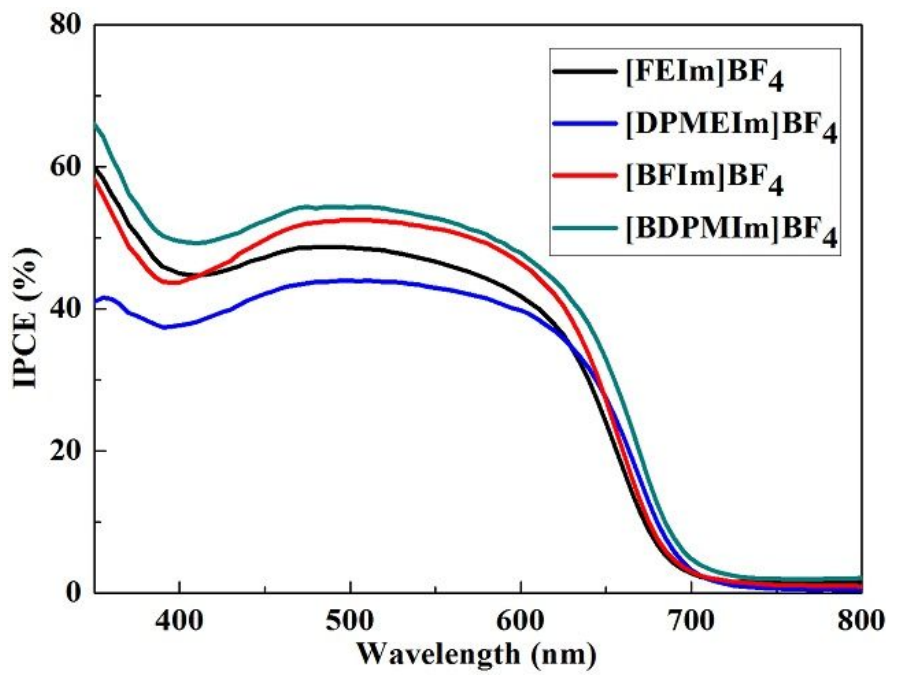

